\title{
Exposing to EMF
}

\author{
Mahmoud Moghavvemi ${ }^{1}$, Farhang Alijani ${ }^{1}$, Hossein Ameri Mahabadi ${ }^{1}$ \\ and Maryam Ashayer Soltani ${ }^{2}$ \\ ${ }^{1}$ Department of Electrical Engineering, University of Malaya (UM), \\ ${ }^{2}$ Department of Bioprocess Engineering, Universiti Teknologi Malaysia (UTM) \\ Malaysia
}

\section{Introduction}

\subsection{Electromagnetic Field Radiation}

In the recent years, by developing the usage of new popular Electronic-Communication gadgets and home appliances like Mobile Phones and Microwave Ovens which are mostly sources of Electromagnetic Wave Radiation, a severe public concern regarding the sideeffects "whether positive or negative" on human health and environment has been arisen. It means that there are new challenging issues rather than old one "the exposing to low radiofrequency emissions" which have been studied for past decades. Indeed, for more than 100 years, human has exposed to the Radio-waves radiation from Radio \& TV broadcasting transmitters besides the Radar and point to point V/UHF/microwave links. However due to the low power density of those high frequency emissions which were far enough, the only low frequency was considered as main and important subject of EMF to human.

To set the limitations on all types of EMF Radiations the "International Non-Ionizing Radiation Committee" INIRC, in cooperation with "World Health Organization" WHO, had started their activities for 4 decades. Their first report to "United Nations Environment Program" UNEP has been approved in 1977. Later in 1992, to professionally study and investigate the detriments of Non-Ionized radiation and its effects on environment, INIRC changed to "International Commission on Non-Ionizing Radiation Protection" ICNIRP. In spite of world activities that have been done so far, it can be easily understood that all kinds of EMF radiations, which we regularly use in industry and/ or in our personal life has become a vital part that we cannot ignore. Therefore, sometimes we expect and also suffer from and its side effects. [1]

In the following sections, the different types of EMF and their characteristics besides of definitions, would be introduced and investigated separately. There are different fields that we use nowadays, i.e.; Electrostatic Field, Magnetic Field and Radio-waves which are our part of interest. It would be showed that the effect of near-field radiation is quite different comparing to RF effect of far-field as we used to know. It means that the closer to the source of radiation there are the new side-effects that we are exposed to. That is important to know that, distinguishing between near and far-field regions for all sources due to their frequency, dimensions and structure are not clarified well and consequently, EMF measuring techniques should be chosen carefully. The engineering techniques for measuring the intensity of radiation is named EMF Dosimetry which would be discussed in the next section and some 
practical measurement ideas would be given. Further, the Biologic effects on live tissues and human body will be investigated for concerned fields. Finally we will discuss on safety techniques and by introducing techniques will give remedies to keep environment safer.

\subsection{EM fields characteristics}

Though the radiation generally refers to all kinds of energy transmission but there is a distinguishing difference between energy levels that cause breaking in molecules boundaries. If the energy is enough to make a change in molecules, we would have an ionized radiation. This can be seen in particle based radiations like alpha, beta, gamma, and $\mathrm{X}$-ray as well as, high levels of frequency and energy. The quantized energy level for such radiation could be calculated from the following equation:[2]

$$
E=h v
$$

In which " $v$ " is the frequency and " $h=6.6260693 \times 10^{-34} \mathrm{Js}$ " is the Planck constant.

As for Radio-Wave Radiation, since the concerned spectrum is lower than $300 \mathrm{GHz}$, normally we don't have those high levels of ionizing energy. So a new term as non-ionizing radiation is used instead. This type of energy based on its components which are Electric and Magnetic fields, presents different phenomenon in terms of frequency, level and direction of field vectors, electric and magnetic characteristics of substance, angles of incident fields and the distance between source and measuring point or the type of radiation-zone.

The Microwave ovens, RF diathermy, RF welding or RF-brazing are good common examples of non-ionizing but effective Radio-Wave radiation sources in our life.

Since the ionizing radiation is not considered here, its definitions, units and scales are not part of our interest consequently. Therefore we prefer to use more tangible scales which are derived from Electromagnetic concepts rather than high energy particles in ionizing radiation. It is important to mention that though the energy levels can be converted between the two types of radiations but for instance the results and effects on human tissues are not necessarily the same. It can be interpreted by effecting mechanism on tissues under test.

According to electromagnetic equations, for the transverse electromagnetic mode wave TEM, when we are far from the source, but in the main axes of radiation, the power density can be calculated from electromagnetic fields' components (Poynting vector):

$$
\mathrm{S}_{\left(\mathrm{W} / \mathrm{m}^{2}\right)}=|\mathbf{E}|(\mathrm{V} / \mathrm{m}) \cdot|\mathbf{H}|(\mathrm{A} / \mathrm{m})
$$

\subsection{Basic concepts}

There are 3 distinguished regions around an EMF radiator which have different characteristics. In the vicinity of source (antenna) where we are not far from $\lambda / 2 \pi$ or $0.159 \lambda$ the fields are reactive and stored in the volume around the source. We name such a region as near-field where $\mathrm{E}$ and $\mathrm{H}$ fields have complex relation and all types of polarizations as Vertical, Horizontal and Circular exists but traveling wave is not observed. In each point, the $\mathrm{E}$ or $\mathrm{H}$ is dominant. Power density cannot be measured since both fields and their phases needed. In this region $\mathrm{E}$ and $\mathrm{H}$ are stored around antenna and propagate as component. The stored energy in shape of self-capacitance or inductance transact to current source by the moving back and forth of energy. In this region any additional conductor absorbs this energy and the energy doesn't return back again. In this condition the energy of 
transmitter is pulled out by outer conductor but as soon as outer circuit closes, power consumes and transmitter loads, like primary and secondary winding of a transformer. Therefore, any simple field measurement in this region is invalid.

Far beyond the reactive near-field zone, up to about 1-wavelength from the radiator, the radiative near-field or Fresnel zone could be distinguished. In this region the power density doesn't follow the $1 / \mathrm{r}^{2}$ law since the $\mathrm{E}$ and $\mathrm{H}$ are not contributed in plane-wave yet. This region is very dangerous for human since far-field measuring equipments do not work correctly. Since we are far from energy storing region, all kinds of radiation could be seen in form of spherical waves. This not-uniform radiation propagates in high speed but mixture of $\mathrm{E}$ and $\mathrm{H}$ components are not same as far-field instead they have phase shifts that don't vary linearly with distance from phase center. In this region re-radiating from metals which acts as parasitic antennas happens and such new antennas also makes its own near-field zone. As exposing mostly occurs by fields components ( $\mathrm{E}$ and $\mathrm{H}$ ), to measure the field we need $\mathrm{E}$ and $\mathrm{H}$ probes. Obviously no pattern and polarization is considered for a source in near-field region. This region extends up to about $2 \lambda$ as transition zone to reach to far-field (Fraunhofer) region. By considering the maximum overall dimension of an antenna as " $\mathrm{D}$ " there is a criterion for distinguishing between these regions as:[4, 5]

$$
\begin{array}{ll}
\text { Near-field: } & \mathrm{R}<0.62\left(\mathrm{D}^{3} / \lambda\right)^{1 / 2} \\
\text { Fresnel Region: } & 0.62\left(\mathrm{D}^{3} / \lambda\right)^{1 / 2}<\mathrm{R}<2 \mathrm{D}^{2} / \lambda
\end{array}
$$

Further than the Fresnel region, we have far-field (Fraunhofer) region which extends up to infinity. The plane-wave with its full characteristics like: radiation impedance $(E / H=\sqrt{ } \mu / \varepsilon=120 \pi \Omega)$, pattern, polarization and mode is valid:

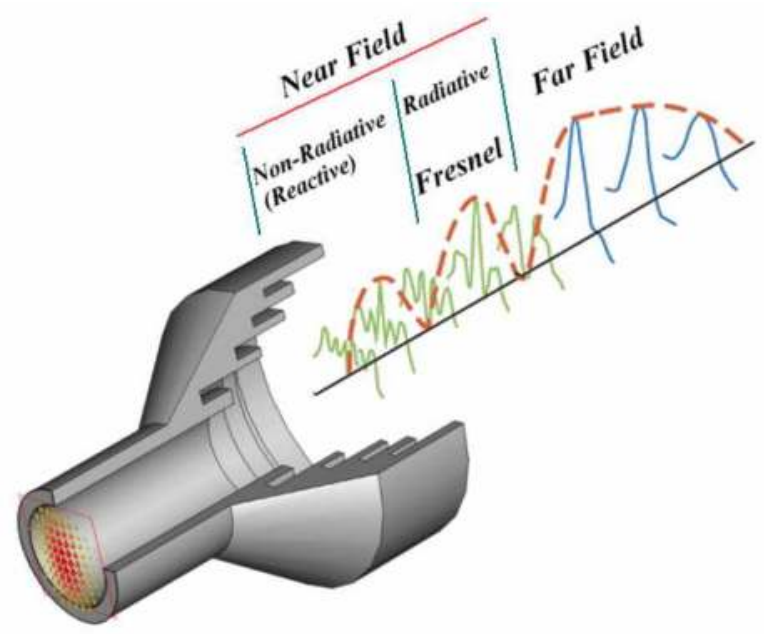

Fig. 1. Near-Field and Far-Field regions for a microwave radiation source sample

\subsection{Polarization}

The Electrical plane for the far field TEM radiation is called polarization plane and the orientation of the electrical component is polarization's direction. As an instance, for the 
following TEM wave, the wave propagation is in x-axes and we consider this wave as a linear vertical polarization the E component is in parallel to $y$-axes.

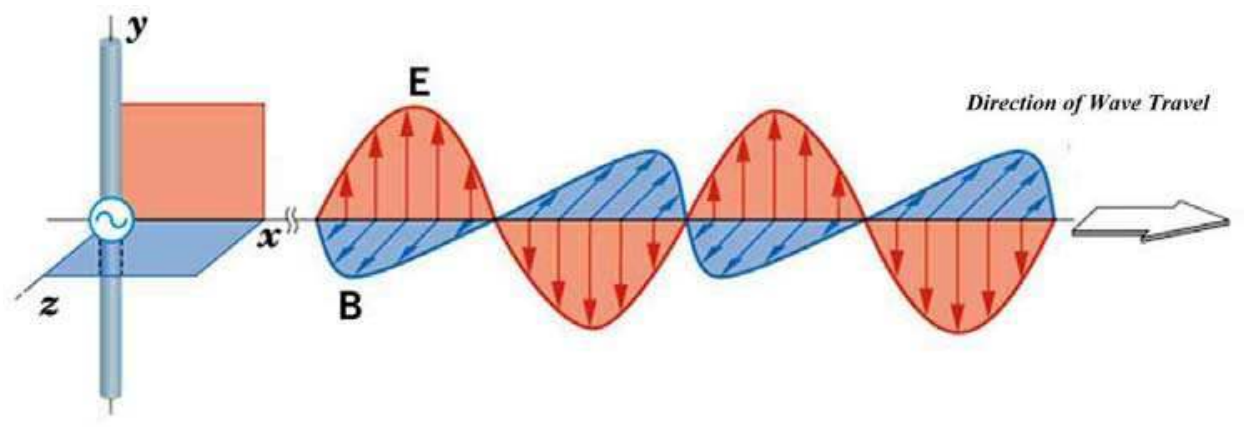

Fig. 2. Plane wave and its components

In reception mode, since the E-field, easily couples an induced current in a conductive material, it is very important to know what the polarization of the incident wave is. Such waves can be stopped easily by putting a conductor in parallel to polarization axes as it would absorb E field energy and eliminating the TEM wave consequently. If the polarization's direction changes by time and for example the E-field vector passes through a circle contour, the circle polarization occurred. It would also goes through an elliptic contour to make an elliptic polarization. This kind of polarization is seen when a plane wave passes through a $\lambda / 4$ dielectric or reflects from a metallic plate in non-perpendicular angle. This is because of dividing each linear polarization into two Right Hand Circular (RHC) and Left Hand Circular (LHC) waves. Anyway, since such polarization cannot be stopped easily by parallel E-field plates, they can easily penetrate into any substances and even our bodies.

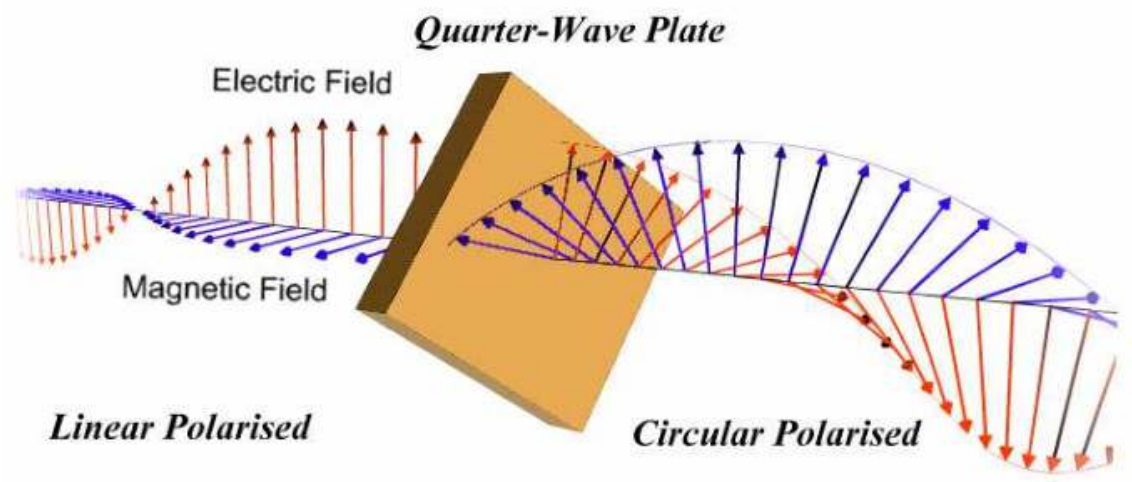

Fig. 3. Generating a circular polarized wave from linear polarized wave

It is so important to know that, if we don't have any idea about the polarization of incident wave, we cannot measure its power and its important parameters. Even the linear sensing dipole, receives half of energy of circularly EMF radiation in any direction of transverse plane. 


\section{Dosimetry}

According to a definition the amount of a substance that is in contact with or exposed to radiation is called as "Dose" and for EMF case we use the expression "EMF radiation dose". The EMF radiation dose represent the different aspects like: induced current density for lower frequency than $100 \mathrm{kHz}$, Thermal effect by using the specific absorption rate SAR $(\mathrm{W} / \mathrm{kg})$ and other non-thermal effects mostly measured by electric or magnetic fields.

For a standing person, the body can couple to a vertical electric field which the induced current is observed in orientation from head to feet and vice versa. However for a properly circulated induction to a standing body, a horizontal magnetic field needed.[6, 7, 14]

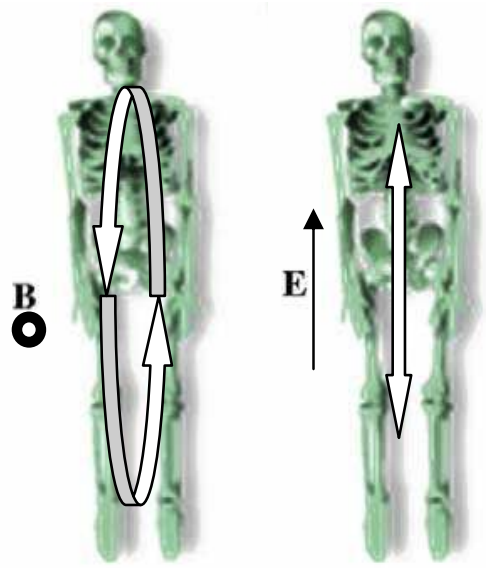

Fig. 4. Coupling of E and B with body

\subsection{SAR}

Specific Absorption Rate (SAR) is the safety criterion in terms of absorbed energy in human tissue. SAR is measured by Watt per unit mass of tissue and shown by $\mathrm{W} / \mathrm{kg}$ and used between $100 \mathrm{kHz}$ and $10 \mathrm{GHz}$. If we know the tissue's electric field $\mathrm{E}$, the conductivity $\sigma$ and the mass density $\rho$ then average SAR can be calculated as: [5 -7]

$$
\mathrm{SAR}=\int_{\text {Sample }} \frac{\sigma(\mathrm{r})|E(\mathrm{r})|^{2}}{\rho(\mathrm{r})} d \mathrm{r}
$$

Usually SAR is determined over a certain mass of tissues, like 1 or $10 \mathrm{~g}$ and for each given values for SAR such condition should be mentioned. As an example, the maximum SAR of a mobile handset determined by FCC, is $1.6(\mathrm{~W} / \mathrm{kg})$ over a volume containing 1 gram of tissue but, CENELEC the European standard gives an average of $2(\mathrm{~W} / \mathrm{kg})$ over $10 \mathrm{gram}$ of tissue.

As a general view, we should know that SAR gives an absolute value and sometimes it could be misleading. So in order to be able to compare the parameters, it is better to issue a standard model for human body. To study the heating effect of EMF on human body, "standard human" has been introduced. The standard human is defined as (height $=175 \mathrm{~cm}$, weight $=70 \mathrm{~kg}$, total surface $=1.85 \mathrm{~m}^{2}$ ). So exposing to $14 \mathrm{~W}$ radio-wave radiation, causes an 
average SAR equals to $14 / 70=0.2 \mathrm{~W} / \mathrm{kg}$. The absorption for each tissue depends on its specific SAR and we cannot use an absolute value to describe total radiation effect.

The specific absorption of energy or "SA", by knowing the specific absorption rate SAR in each tissue can be defined by:[6]

$$
\mathrm{SA}_{(\mathrm{J} / \mathrm{kg})}=\mathrm{SAR}_{(\mathrm{W} / \mathrm{kg})} \times \text { Exposure time }_{(\mathrm{Sec})}
$$

Relative heath capacity is determined as:

$$
\mathrm{C}=\Delta \mathrm{Q} / \Delta \mathrm{T}
$$

$\Delta \mathrm{Q}$ is the amount of heat due to a $\Delta \mathrm{T}$ rise in temperature. For unit of mass the relative heath capacity is describe as:

$$
\mathrm{C}_{\rho}=\mathrm{C} / \mathrm{m}\left(\mathrm{J} / \mathrm{kg} \cdot \mathrm{K}^{\circ}\right)
$$

As an example, $\mathrm{C}_{\rho}$ of the water (liquid) at $15^{\circ} \mathrm{C}$ and $\mathrm{P}=101.325 \mathrm{kPa}$ is:

$$
\mathrm{C}_{\rho}(\text { water })=4.1855\left(\mathrm{~J} / \mathrm{kg} \cdot \mathrm{K}^{\mathrm{o}}\right)=4185.5\left(\mathrm{~J} / \mathrm{g} \cdot \mathrm{K}^{\circ}\right)
$$

Therefore, by knowing the absorbed energy and exposure time, increasing the temperature of tissue by relative heath capacity of $C_{\rho}$ for unit of tissue mass due to such energy is derived as:

$$
\Delta \mathrm{T}_{(\mathrm{Deg})}=\mathrm{SA}_{(\mathrm{J} / \mathrm{kg})} / \mathrm{C}_{\rho}
$$

So exposing to $\mathrm{SAR}=4(\mathrm{~W} / \mathrm{Kg})$ at 15 minutes can cause an increasing $1^{\circ \mathrm{C}}$ in human body when there is no cooling system like blood circulation. [6]

Considering a $\Delta \mathrm{T}_{(\mathrm{Deg})}=1 \mathrm{OC}$ temperature increase in human tissue can be considered as the first restriction criterion for exposure as a rule of thumb.

\begin{tabular}{|lll|}
\hline Tissue & C (J/kg.Co $)$ & Density $\left(\mathrm{kg} / \mathrm{m}^{3}\right)$ \\
\hline Skeletal muscle & 3470 & 70 \\
Fat & 2260 & 940 \\
Bone, cortical & 1260 & 1790 \\
Bone, Spongy & 2970 & 1250 \\
Blood & 3890 & 1060 \\
\hline
\end{tabular}

Table 1. Specific capacity and density [19]

For exposing to EMF, It should be mentioned that like what we use in microwave ovens there are 2 major factors pair of Time and Power density.

Unfortunately, measuring the SAR in real is not practical so in simulations, the models of human body or plastic dolls (phantom) are used. Since the body is not electrically homogeneous usually the models are filled by same dielectric characteristic absorbing materials and heat can be measured by infra-red camera analyzers. 


\subsection{Induced current density}

According to Maxwell's equations the conductivity and permittivity are in relation together. The induced current based on electric field is expressed as:

$$
\vec{J}=(j \omega \varepsilon+\sigma) \vec{E} \quad\left(\mathrm{~A} / \mathrm{m}^{2}\right)
$$

By expanding the permittivity in complex form of real part as dielectric constant, and imaginary part as dielectric losses:

$$
\varepsilon_{r}=\varepsilon_{r}^{\prime}-j \varepsilon_{r}^{\prime \prime}(\mathrm{F} / \mathrm{m})
$$

Indeed $\varepsilon_{r}^{\prime \prime}$ is a measure of both the friction of changing polarization and drift of conduction charges.

While their ratio is the tangent of loss angle:

$$
\tan \left(\delta_{e}\right)=\frac{\varepsilon^{\prime \prime}}{\varepsilon^{\prime}}
$$

By combining these equations, we have:

$$
\vec{J}=\left(j \omega\left(\varepsilon_{r}^{\prime}-j \varepsilon_{r}^{\prime \prime}\right)+\sigma\right) \vec{E}=j \omega \varepsilon_{r}^{\prime} \vec{E}+\left(\omega \varepsilon_{r}^{\prime \prime}+\sigma\right) \vec{E}
$$

The real part of equation is the relation between electric field and current:

$$
\sigma_{\text {eff }}=\left(\omega \varepsilon_{r}^{\prime \prime}+\sigma\right)(\mathrm{S} / \mathrm{m})
$$

The equation shows the frequency dependence of conductivity. Though the best way for calculating the SAR based on induced current is measuring the current in tissues but in real situation, such a measurement is very difficult. So simulating the current by knowing the electrical characteristic is the way that is used. [10]

$$
S A R=\frac{\sigma|\mathbf{E}|^{2}}{\rho_{m}}=\frac{\omega \varepsilon_{o} \varepsilon^{\prime \prime}|\mathbf{E}|^{2}}{\rho_{m}}
$$

The geometry of human body determines the type of induction. In case of isolated feet from ground we consider an un-grounded case. And in case of bare foot the image of human contributes to make a double size of body that cause a half resonance frequency in compare to un-grounded human. In case of grounded, the area around the ankles might be burned due to maximum current.

The following values are used for modeling a human body to calculate the SAR [7] :

\begin{tabular}{|lccc|}
\hline Tissue & $\sigma(\mathrm{S} / \mathrm{m})$ & $\varepsilon_{\mathrm{r}}$ & $\rho\left(\mathrm{g} / \mathrm{cm}^{3}\right)$ \\
\hline muscle( high water content) & 46 & 2.3 & 1.1 \\
fat (low water content) & 5.5 & 0.15 & 0.9 \\
\hline
\end{tabular}

Table 2. Characteristics of main tissues for modeling 


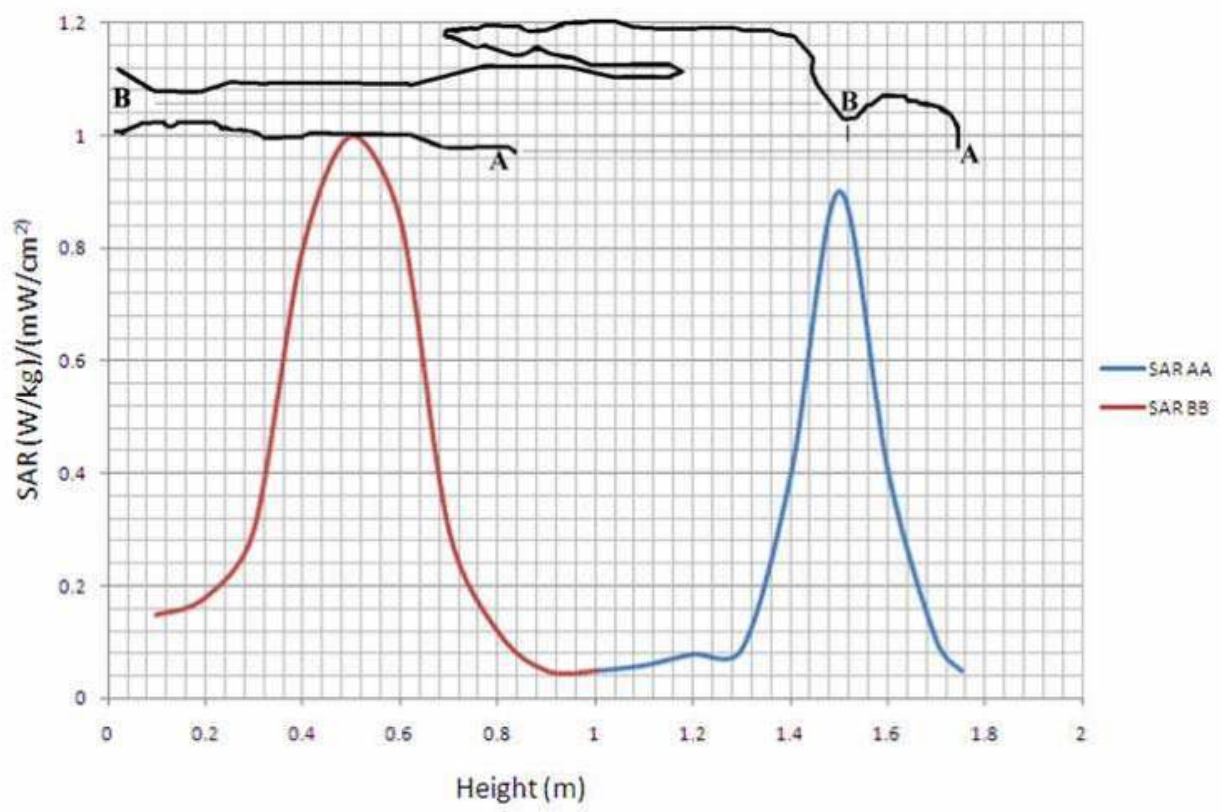

Fig. 5. Calculated SAR along a model in two sections of standard human body. [10] The incident wave is $1 \mathrm{~mW} / \mathrm{cm}^{2}$ on the surface, frequency $=350 \mathrm{MHz}$

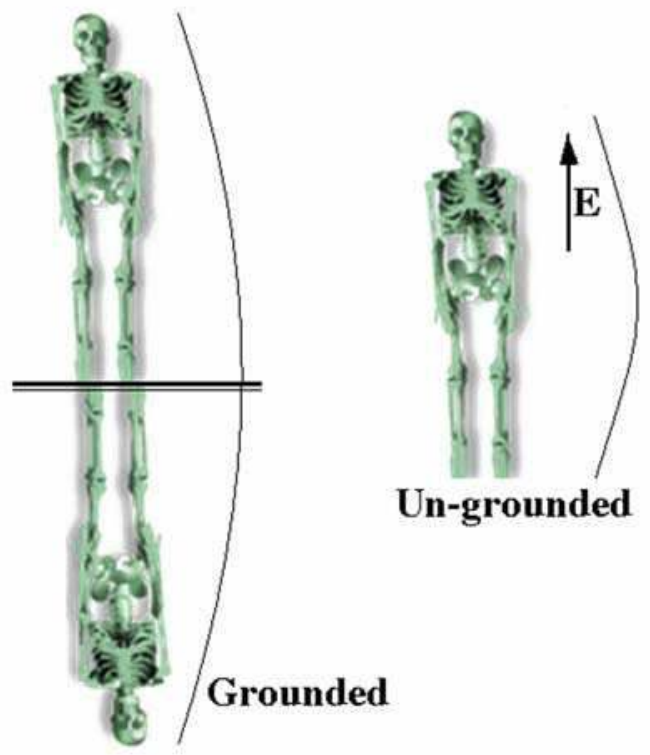

Fig. 6. Electric field induced on grounded and un-grounded human [14, 6] 


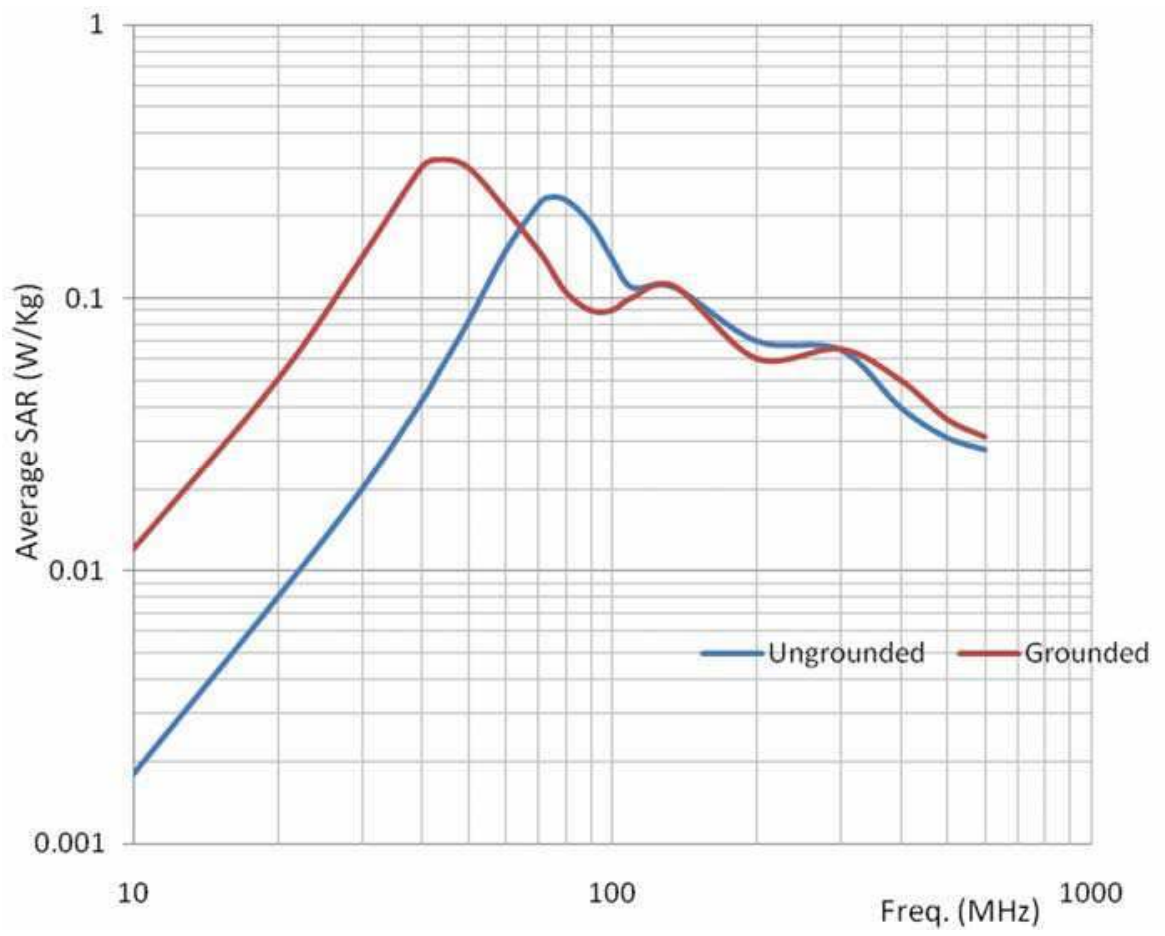

Fig. 7. Resonance of body and SAR. Below resonance the SAR varies by $\mathrm{f}^{2}$ and beyond resonance by approximately $1 / \mathrm{f}[6]$

\subsection{Interaction characteristic}

When we are in near-field, the body (tissue) which is under dosimetry's test interacts to fields which perturb the fields consequently. In near-field we have a coupling model between body (tissue) and source that cause changes in the source impedance. The high impedance sources tend to give a high electric coupling to electric fields and low impedance sources tend to couple to magnetic fields.

In real, some EMF sources can be considered as near-field, like mobile handset phones which we keep them on our ear/ head that directly couples its energy to our head and brain. By considering their maximum power when they working in far regions to compensate the link budget losses we cannot ignore its role in EMF near-field exposure (up to about $5 W)$.

Leaky wave cables, RF loose connections, BTS Tx/Rx on roofs, high order modes or NonTEM ducted waves in buildings, transmitters in tunnels are all can be considered as samples of Near-Field Sources.

\subsection{Exposing to VLF and low frequency EMF}

Electric fields can induce surface charges on body and cause a surface current consequently. The position of body and its size, conductivity of skin tissues and direction of Electric vector for evaluating the exposure effects, are all important. 
The low frequency magnetic fields cause an induced circular current on human body. The magnitude of field and current density depends on circle's radius of current's contour, tissues conductivity and magnetic flux density.

For Magnetic Resonance Imaging, usually high power magnetic field used to penetrate body. Exposing to such fields also limited and in standards like IEC 60601-2-33, the suggested values are given. As a brief result, the maximum $2(\mathrm{~W} / \mathrm{kg})$ for whole body at 6 minute exposing is recommended. $[12,6]$

\subsection{Field measuring techniques}

The best measuring method is the one that makes minimum level of perturbation on the existed fields. It means that we should use the smallest probe or sampler inside of the field to measure it. In addition we know that small antennas provide a broadband response. But its gain would be limited due to small size. For this reasons, using the normal dipole or LPDA as broad-band antenna has serious restrictions in measuring the fields and especially dosimetry applications.

Instead, very small electric probe by electrical gap can be used as an element of E-Field sensor. In real, isotropic E-field probe with 3 orthogonal small dipoles usually used and give an rms values to readout device. This E-probe has an easy operation. In order to keep sensors away of contacting to illuminators or resources, the spherical foam-cap used to cover the head of probe.

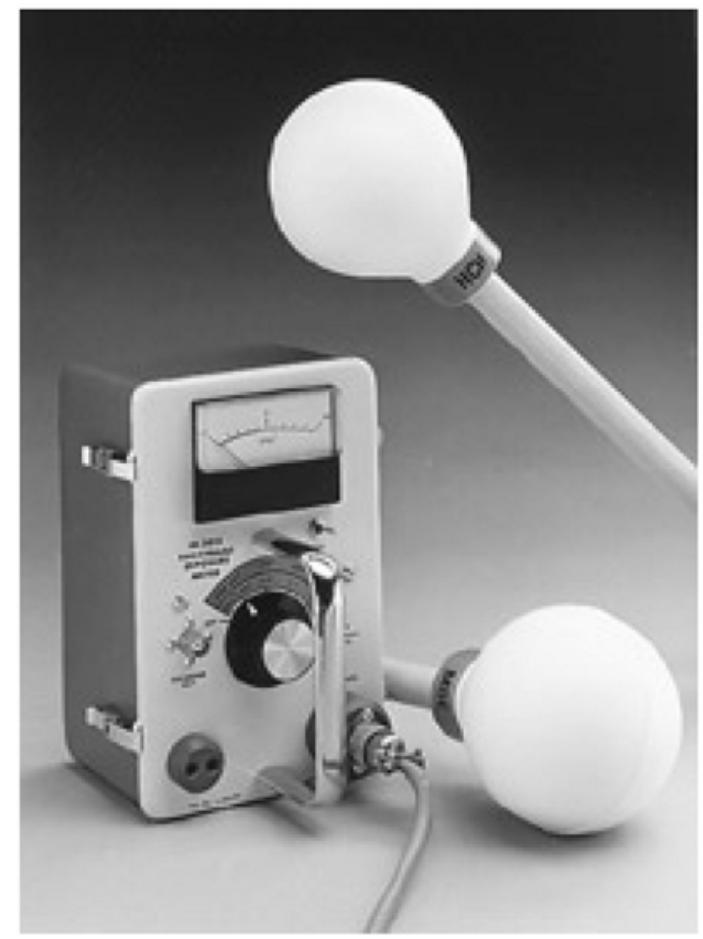

Fig. 8. Electric and Magnetic Field meter. Readout device is same for E and M probes 
The B-field sensors are made by using the very small magnetic dipole by small loop. It is usually constructed by 3 orthogonal small loops (for 3 dimensions) as isotropic probe with common readout unit with E-field instrument. This sensor can be used up to $1 \mathrm{GHz}$ and $\mathrm{H}$ can be obtained by $\mathrm{H}=\mathrm{E} / 120 \pi$ if we have a plane wave metering.

Another type of sensors is synthesized by resonant antenna. Such antenna is narrow-band in frequency response but has smaller size and higher efficiency in reception. Such meters are good enough for especial applications but as general metering tool, they are not useful since their polarization is usually fixed and k-factor of antenna is not valid for near-field measurement.

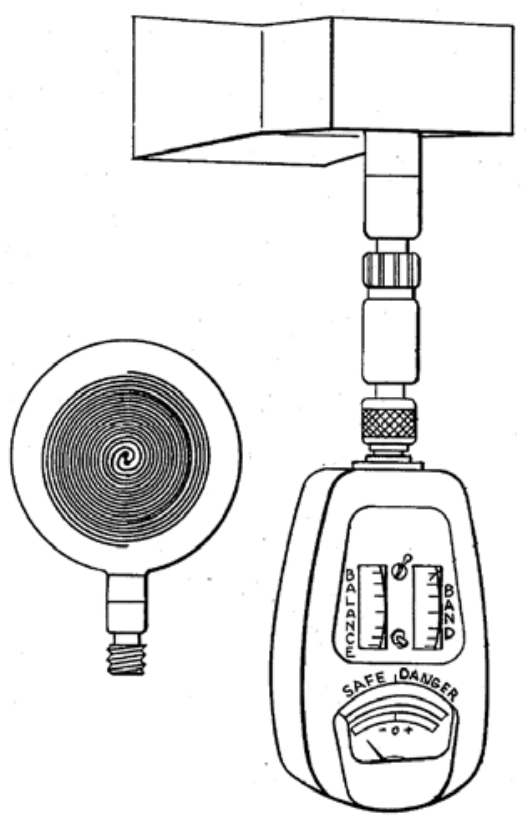

Fig. 9. Two samples of E-probe that are based on wide-band antennas. Any wide-band and narrow-band probes can be used with same readout meter if their size is small enough. Such antennas are directive (whether wide-band spiral or horn) in pattern and are not suitable for isotropic EMF exposure metering

There are other sensors used for low frequency applications based on Pockels-effect (E-field sensor) and Hall-effect (B-field sensor). The size of such sensors is small enough to use them in many applications easily.

For pulsed field measurement and dosimetry applications especially in near-field where electric and magnetic fields have high variations that cause big problem in metering, as we have seen before, it is better to use thermocouple detector rather than diode. This method easily works up to $18 \mathrm{GHz}$ and more. The thermocouple directly converts existed fields that make the heat in matters. There is not an estimation or prediction in metering as we have in E or M-probes cases, while we directly readout the correct values of both fields (mixed) that we needed. [14] 


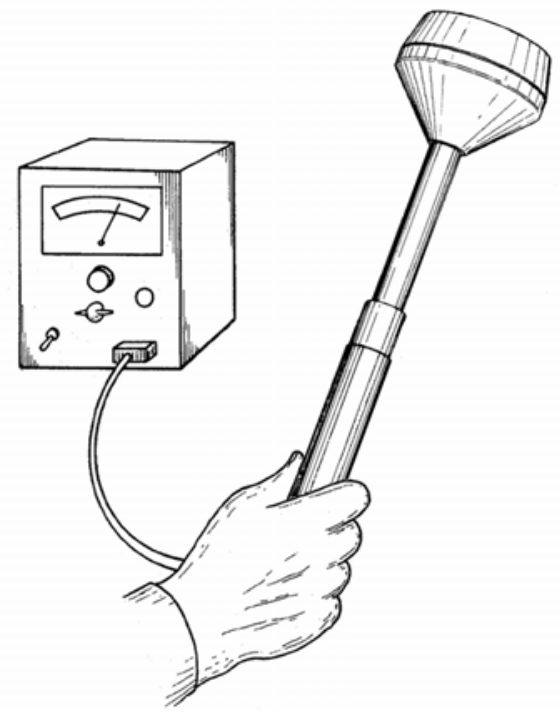

Fig. 10. Common Thermocouple Dosimeter. This design has been used for more than 60 years. The wideband thermocouple in probe's head makes it the best solution for Radiation dosimetry

\section{Biologic effects}

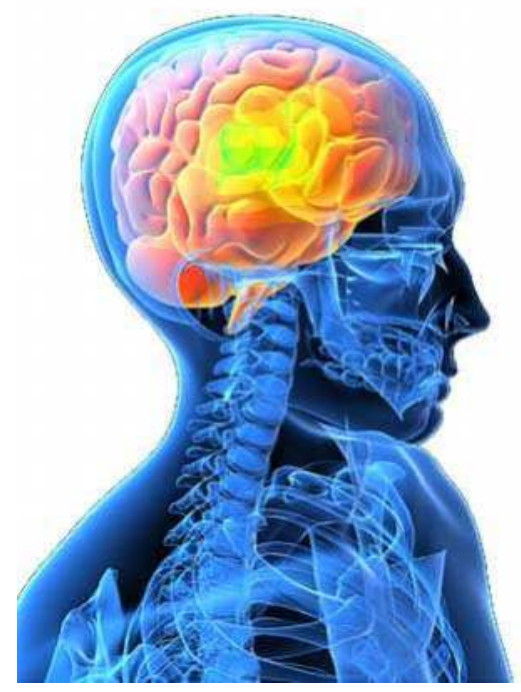

Fig. 11. Brain and nervous system are easily threatened by EMF exposure

Exposing to Radio-Waves radiation does not make the same effects in children and adults. The size and electromagnetic characteristics of children's body is completely different to 
adults and cause multiple risk ratios in EMF exposure. In addition, we also can add the interfering effects risk by non-heating but biochemistry side effects to growth hormones of glands, which as we expected are in high level for children. That is why the maximum amount and frequency of EMF, in different age groups are the case of study for standard organizations. As we know, EMF lowers our melatonin levels, which control our immune system response to cancer and other diseases. By considering all side-effects, therefore, we are expected to have a practical and handy table for such limitations in terms of age, frequency and other parameters. But unfortunately such table is not available easily.

In order to better realization and study of such effects on body we can start by known symptoms. It means that such effects should be analyzed from different points of view. Thereafter derivation of charts and analyzing reports can be done easily by merging those results together.

\subsection{Heating}

Absorbed EMF radiation simply deposits its energy by heating the material. Tissues heating due to absorbing the electromagnetic fields can be seen in full range of radio-waves. But in spite of tangent of the loss or relative permittivity which is important in high frequencies, the exceeded current density due to its conductivity in tissues causes a problem in the low frequencies too.

The heating by absorption of EMF completely depends on frequency. For low frequencies $(100 \mathrm{kHz}$ up to $20 \mathrm{MHz}$ ) the neck and feet are the most absorbed parts.

In the frequency band of $(20-300 \mathrm{MHz})$ we have a higher absorption in full body and much more in resonated parts like the head. In the (300MHz up to some $\mathrm{GHz})$ the absorption is based on non-uniform and mostly considered as regional. In case of $(10-300 \mathrm{GHz})$ we can expect the most absorption is in skin and outer small tissues like eyes and gonads which can show the resonance effects as well. [8-10] What we expect to know is that intense radio waves can thermally burn living tissue same way as we can cook food in microwave ovens!

As we know, human's body fulfilled by a high percentage of water. Water molecules can be polarized due to its molecular structure $\left(104.5^{\circ}\right.$ between $\left.\mathrm{H}-\mathrm{O}-\mathrm{H}\right)$. So the human tissues which have high amount of water are able to be affected by magnetic fields too. The water's molecules forced to follow the magnetic field of incident EMF but due to its lag in vibration the excess energy converted into heat.

There is an adjusting system in human body to fix the body's temperature. Over-exposing to EMF can increase the human's body temperature and hyperthermia occurred consequently. Even increasing the 2.2 degrees in human's body destroy the tissues cell and needs the special treatment and sever cure. Fever is the common symptom that everybody is familiar with and can give a tangible and good idea for understanding the body temperature increasing. Usually the maximum SAR levels depends on many factors like: weight, age, equivalent EM characteristics of tissues and body dimensions but as for standard human mostly the $0.4(\mathrm{~W} / \mathrm{kg})$ is the safety limit introduced for healthy people and for occupational exposure case while an additional safety factor of 5 suggested for public case as $0.08(\mathrm{~W} / \mathrm{kg})$ [12]. It also means that for an un-healthy people, the standard is much different. Noticing to this point is very important in using the standard tables. 
Just like any exposed material to EMF, an effective penetration depth can be considered for human tissues too. It is where each of field levels degrades by $1 / e$ (Euler's constant). Therefore by degrading the $e^{-2}$ we have drop down of power density to $13.5 \%$. This depth depends on wavelength and decreased by increasing the frequency. By considering the saturation level of water in tissues and environment humidity, such following curve derived over the radio frequency band [13].
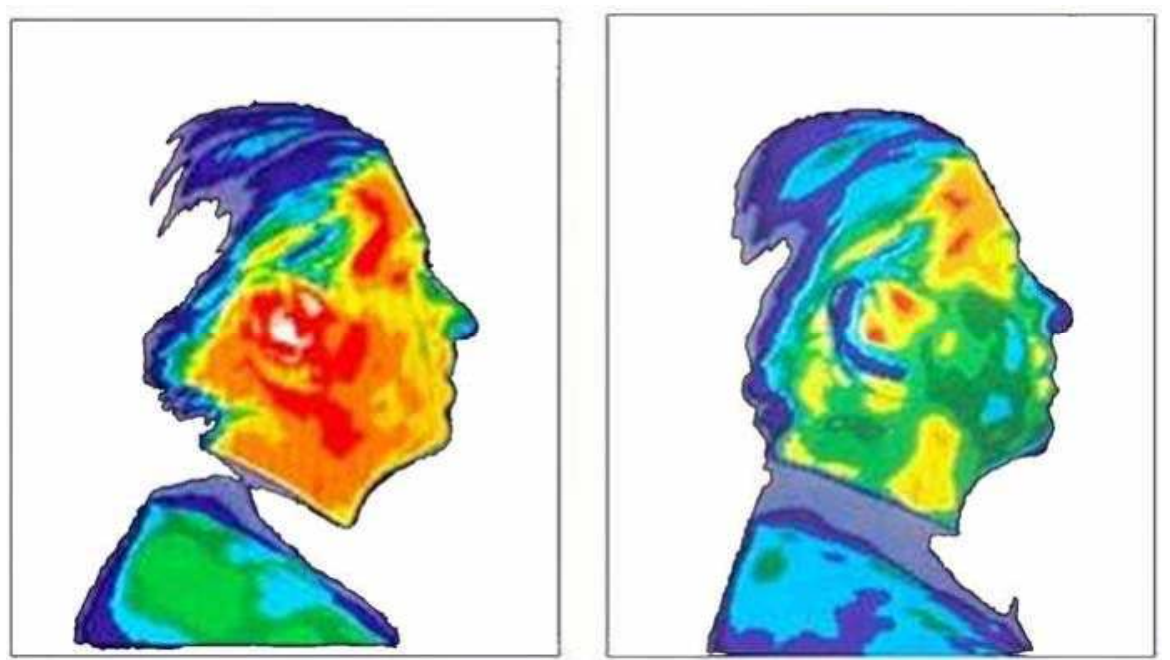

Fig. 12. Thermo-graphic image of the head, Right: no exposure. Left: A 15-minute phone call

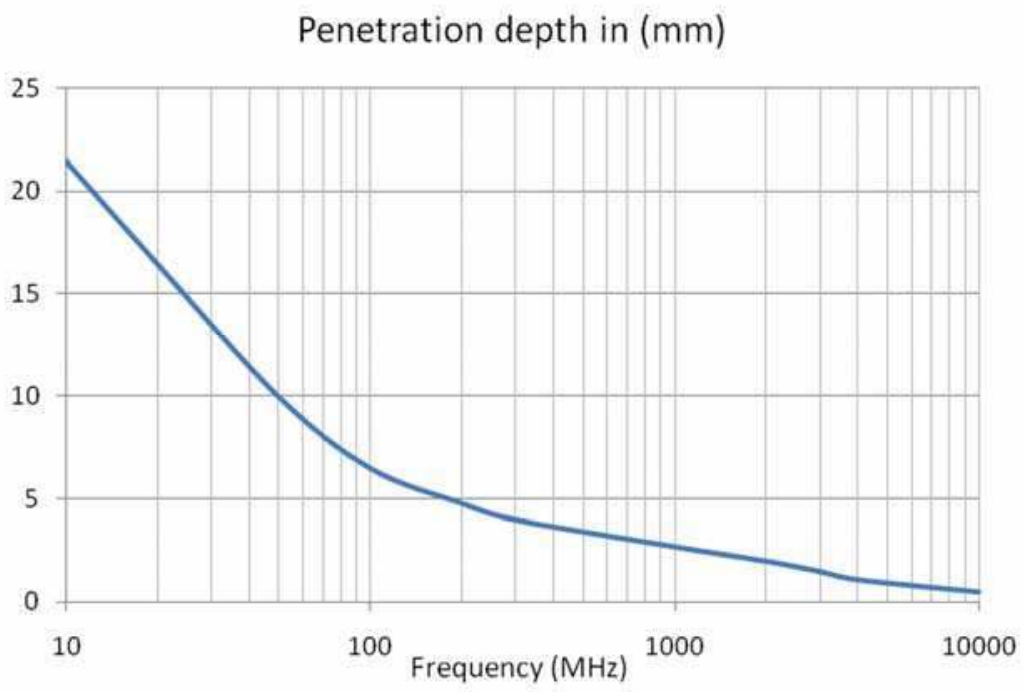

Fig. 13. Sample of penetration depth and its dependency to frequency 
This penetration depth can lead us to this fact that $86.5 \%$ of incident energy should be dissipate and absorbed in such layer of skin and not affecting on whole body. In other words, for high frequencies we don't involve whole body's weight and meanwhile, skin tissues can burn easily even by not a high power density [11].

The human body like any mixed-dielectric structure can show the resonance frequency. It means that in certain frequencies and in that specific body's position the amount of SAR can raise to a maximum. In other words standing, sitting, lying and so on, have different response to SAR. In resonance of radio-waves the maximum size of body which is parallel to electric field's direction (polarization) is important. So for standing case, by considering the average relative dielectric value as we have seen before, the resonance occurred when the height is about $\lambda_{r} / 2$. Therefore, in case of standard human we have:

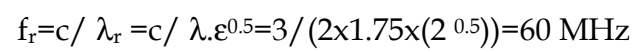

This amount is just for estimation and in real case by considering the different tissues and organs; we should consider each case one by one. Obviously, this frequency is going higher for shorter people and kids. As for instance the resonance frequency for 1-meter tall boy would be around $120 \mathrm{MHz}$ and for 0.5 meter infant is around $240 \mathrm{MHz}$.

In addition to mentioned effects we have seen the hot spots regions in EMF exposed body too. The hot spots usually occurred due to non-uniformity of EM characteristics of tissues. Because of such mixed structure, the power density is not distributed uniformly between tissues, and in some parts that tangent of loss or SAR is higher it could have maximum temperature. The organic parts that cannot be cooled by blood circulation are the weakest parts in terms of radio-wave radiation. The eyes and gonads are the most sensitive parts since there are not enough vessels for cooling down by blood circulation.

The major effect of EMF on eyes could be the cataract in which the lens clouded. This effect is especially very important when the microwave radiation is considered $(10-300 \mathrm{GHz})$ but the destruction completely depends on how incident waves enter eyes in terms of polarization, power, duration, and human personal factors. As ICNIRP recommended, by limiting the power density to lower than $50 \mathrm{~W} / \mathrm{m}^{2}$ eyes defects could be controlled. The SAR for some animal eyes has been measured. As an example the measured SAR is about 100 up to $140 \mathrm{~W} / \mathrm{kg}$ for rabbits. Therefore EMF exposing in long duration (more than an hour) would increase the eye's temperature up to some degrees which is very harmful. The experiments on rats proved that there is a direct relation between EMF exposing and disability in fertility due to gonads' temperature which has risen by EMF. It is interesting that the effects on sleeping groups are more than awaken groups. In other words the threshold SAR level is lower for sleeping people. This could be explained by temperature auto adjusting system by blood circulation which is in rest during sleeping.

It may be seems strange, but the ears are also able to feel (hear) some radar's high pulsed power. By different experiments on volunteers the power density threshold of $\left(4-20 \mathrm{~W} / \mathrm{m}^{2}\right)$ for frequency range of $(200 \mathrm{MHz}-3 \mathrm{GHz})$ by PRF of 200 and $400 \mathrm{~Hz}$ could be heard. But it was cleared that peak pulsed power was more important than average power and some perception by brain was involved in hearing the microwave pulses [6]. In following table, some clinical symptoms are given. It shows the direct relation between symptoms caused by exposing to EMF. 


\begin{tabular}{|lllll|}
\hline \multicolumn{1}{|c}{ Source } & $\begin{array}{c}\text { Ave. } \\
\text { Power }\end{array}$ & $\begin{array}{c}\text { Exposing } \\
\text { duration }\end{array}$ & $\begin{array}{c}\text { Power } \\
\text { density } \\
\text { Wm-2 }\end{array}$ & $\begin{array}{c}\text { Clinical/Biological } \\
\text { Symptoms }\end{array}$ \\
\hline Radar 3GHz & "high" & $5 \mathrm{~h}$ & $300 \sim 700$ & Heat, Headache, Vertigo \\
Radar 9-10GHz & & $80 \mathrm{sec}$ & $600 \sim 900$ & $\begin{array}{l}\text { Increasing in Creatine } \\
\text { kinase }\end{array}$ \\
$\begin{array}{l}\text { microwave oven } \\
2.45 \mathrm{GHz}\end{array}$ & $600 \mathrm{~W}$ & $5 \mathrm{sec}$ & & Neuropathy \\
wood heater 20kW & $20 \mathrm{~kW}$ & $2 \mathrm{sec}$ & & Burn metallic material \\
wood heater 20kW & $20 \mathrm{~kW}$ & $26 \mathrm{sec}$ & & Oedema, paresthesia \\
$\begin{array}{l}\text { UHF TV antenna } \\
1.75 \mathrm{~kW}\end{array}$ & $1.75 \mathrm{~kW}$ & 1 to $2.5 \mathrm{~min}$ & $>200$ & Diarrhoea, dysesthesia \\
\hline
\end{tabular}

Table 3. Some reported EMF exposing clinical effects $[17,18]$

\subsection{Burning and shocking}

Burning or shocking can be seen by contacting to conductive materials inside of the EMF. This effect can be separated from indirect effect of EMF on implanted circuits like pace maker or ear-amplifiers. Indeed, the induced current in body due to exposing in magnetic field occurred. Such induction especially in lower part of body which contacted to ground has higher amount. Since the ankle cross section is lower than other parts of leg, therefore the high current density may cause a burning in tissues there.

For frequency lower than $27 \mathrm{MHz}$ an empirical formula used for evaluating such induced current [6]

$$
\mathrm{I}_{(\mathrm{mA})}=0.108 \times \mathrm{h}_{(\mathrm{m})} \times \mathrm{f}_{(\mathrm{MHz})} \times \mathrm{E}_{(\mathrm{V} / \mathrm{m})}
$$

Further by simulation techniques this burning effect has been modeled. The shoes have a great role in controlling the maximum current in feet that reduce it to $0.6 \sim 0.8$ of its peak [9]. Other phenomenon that causes burning is happened when we touch metallic parts which have HF, high induced currents on. As soon as the connection occurred the high density of current passes through junction and it could cause a sever injury. Usually we named such effects as shocking and it considered as side effects of EMF on our body. There are lots of instructions and recommendations like the ones issued by WHO/IRPA or ICNIRP98 for reducing such effects in sites.

\subsection{Non-thermal effects}

As we have informed the Non-ionizing radiation is considered to be essentially harmless below the levels that cause heating since absorbed EMF radiation simply deposits its energy by heating the material. But how much this is true? 
Such non-thermal effects can be seen by direct effect of EMF to biological tissues without making a significant heat effect. There are lots of researches done so far on finding out the relation between EMF and cancer tumors. The reports presented contradiction results by different research groups and seems need to work more. What we would expect is that EMF can affect on DNA, Genes, Nervous system and totally Biochemistry of body which is under control of hormones. Therefore even the unknown illness symptoms, may have a root in our EMF polluted environment. There are some experiments on ELF magnetic exposure and its relations to brain cancer and leukemia as reported [13]. Based on epidemiologic studies for field magnitude of $0.3-0.4 \mathrm{~T}$ it was shown the possible carcinogenic relation to childhood leukemia.

\subsection{Treatment by EMF}

All discussions till now were about un-wanted EMF radiations. But, if we can raise the temperature of a tissue by EMF, we can use it for medical treatment as well. This is the basic idea for lots of methods that we have done so far in medical world. Nowadays we use EMF to make a faster healing in broken bone. In addition, EMF can kill the unwanted cells like cancer cells. This treatment named radio-therapy and it can be used as adjunctive therapy besides of regular methods like chemical-therapy. Heating the prostate gland by EMF also used for keeping it small as a treatment and considered as safe and fast treatment without a need to surgery.

Today, EMF treatment generally is used for fast bone repairing, nerve and immune system stimulation, blood circulation and wound treatment, osteoarthritis, tissue regeneration, electro-acupuncturing as well as using the pulsed EMF and low frequency exposure for softtissue injuries [16, 17].

\section{Safety techniques}

Safety techniques derived from simple rules. In real, safety refers to a number of predictions and preparation to prevent exposing or reducing the exposure to as low as possible. So we can start from main issues that have well worth to remember [10].

1. Wetter materials (muscle) are lossier than drier (fat, bone) materials.

2. For parallel E-field to the body's longitudinal axes, SAR is higher.

3. Sharp edges, concentrate E-fields.

4. Parallel conductor has a high perturbation on E-field rather than perpendicular conductors.

5. Penetration depth decreases by increasing frequency and conductivity.

6. Below resonance frequency the SAR varies by $\mathrm{f}^{2}$

7. Small objects compared to wavelength cause minimum perturbation on fields

By noting to those items and referring to charts and equations given in last sections, here are the most important safety issues that we could list: [7]

- The safety level for whole-body average SAR should be less than $(4 \mathrm{~W} / \mathrm{kg})$. This value is measured by average power absorbed over a 6 minute interval per total body weight.

- The maximum partial-body SAR could be up to 20 times of the whole-body averaged SAR $(80 \mathrm{~W} / \mathrm{kg})$. This parameter is defined by strongest radiation over the specified volume like $1 \mathrm{~cm}^{3}$. 
- The product of power density and exposure time should remain below the safe values for sensitive organs such as eyes and testes. The key point is increasing the temperature in organs.

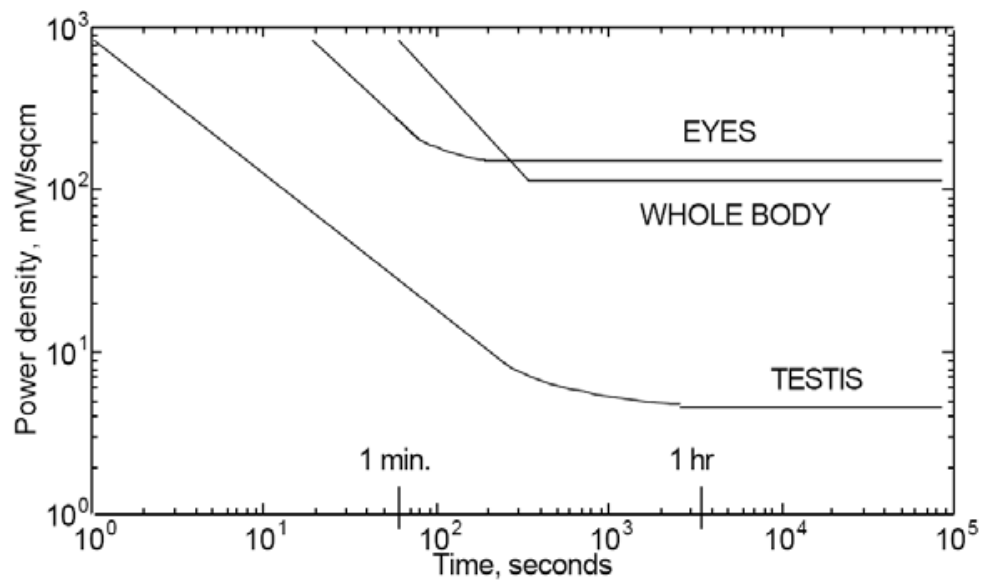

Fig. 14. Threshold levels versus time for sensitive organs [7]

- $\quad$ The current induced in the body due to radiation power density should be low enough to prevent any shock or burning by contacting to metals or conducting materials.

\subsection{New technologies}

The technology of making light weight electromagnetic absorbers developed to making them popular in our used equipment or devices. By using a number of small resonant antennas that loaded to their matched load, and incident waves damped consequently, we can have a high EMF isolation. Though, these absorbers are designed for far-field, but they can also be used in near-field too. The various spiral and crossed slot antenna were used in past, but fractal antenna are recently introduced to determine the characteristics precisely. Meanwhile there are good progresses in designing of antenna. Such development helps us to keep the unwanted EMF radiations as low as possible. As an example, the main antenna beam of some cell-phones is outward of head. And they use some RF dampers to keep head as cool as possible. In addition, by new technologies, we use the least energy and power for devices. Therefore unwanted emissions are lower than before.

\subsection{People duties}

Since safety has different aspects, it is impossible to have a safe environment without noticing to people acts and duties as they are main users of such facilities. Here, some ideas to control such unwanted exposure are given:

- Leaving the Hot area: Since, feeling the heat in body, mostly happened when temperature rose due to EMF exposure for more than a minute, and the skin was able to sense the EMF only in UHF/SHF. So in case of feeling a heat, leaving the site is strongly recommended for operators and technicians even the power density is lower than standard threshold. As it was showed, the standard limitations are not 
considered as guarantee levels for not feeling the heat, and if someone feels heat, it means that it has passed far above standard of safety. Remember that, standards are based on statistical analysis but, replying to EMF is not same for all people. Everyone can have its own personal standards based on his/hers body's electrical characteristics.

- Escaping from resonances: exposing to frequencies near to resonance of our body has higher effect. Even the source power is not too much, the body can absorb and store as much as energy in vicinity of resonance frequency. Therefore, by knowing the emitted frequency, the threshold of hazardous understood. It can also be investigated by Spectrum monitoring of places of concern.

- Don't forget to use suitable shoes to reduce induced currents through feet. This recommendation is important especially for technicians of high power RF equipments, like Radio and TV broadcasting transmitters, Microwave wood drier, RF technicians in Diathermy Clinics, Radar technicians and so on.

- Don't forget that standards limitations are for healthy people. If you are not healthy or have a medical problem, the threshold values for you are very lower than others.

- Restrict using the cell-phones. Use a corded device that allows you to talk on your phone without holding it next to your head. There is some evidence that cell-phone use has caused an increase in brain tumors.

- Don't forget that EMF radiation inhibits melatonin production, which is most active during sleep.

- Don't keep your cell-phones near your bed. Use a corded telephone rather than wireless type if possible. Locate the base of wireless telephone away from beds.

- Reducing the cell-phone's call duration. Standards are for 3-6 minute duration call. Talking in longer time means higher EMF exposure.

- Avoid calling cell-phone when the radio coverage is not fulfilled. In this case, BTS increases its power and send a command to hand sets to increase their power too. It is to keep the link budget between BTS and handset in proper margin. Now, the mobile handsets consume higher power and emit more RF. This can also be checked by battery's discharge speed in such areas.

- Use EMF-protected mobile handsets that used beam forming techniques towards out of head.

- Hug the babies in RF zones. This item may seem to be strange, but as mentioned, the infants and kids have smaller dimensions and have higher resonance frequency. They are so sensitive to EMF exposure than adults. In addition, since they are in their growing age, their growth hormones are in high level, so any even low interfering to their organic system of adjusting hormones, remains the un-returnable side effects that its symptoms can be seen many years later. Besides of mentioned issues, there are some un-proved evidence between EMF, cancer and tumors in children. Therefore, in order to get rid of such worry, we recommend keep babies out of hazardous zone and hug them. It can help to protect from high resonance frequency by uniting the bodies altogether, prevent from direct expose to EMF as supporter buffers a plenty of radiation. Reducing the induced current as they are in higher altitude from ground and supporter's body divide the induced current between kid and itself as well as keeping the frequency resonance as low as possible to reduce intensity of the current. 
- $\quad$ Try to live away from high-power lines or cell phone BTS masts. They are installing in different places even on our home's roof. They may be the highest EMF hazard in near to our living place.

- Use a shielded glass for windows if they are exposing from the EMF transmitters. Using a metallic net by maximum $\lambda / 10$ in mesh size can make a good shield for windows.

- Try to damp the EMF inside of our room by RF absorbers. Using the metal shield without having the idea about RF and its incident direction, doesn't stop the waves and may differ them toward a more sensitive place.

- Stand away from microwave ovens while they're in use. Restrict using of them as low as possible. They can be used only for warming the food and not cooking. They have two effects. First, on our body by RF leakage. Second, on our food by direct effect on its molecules. So try to put these ovens inaccessibility of children since they are curious to watch inside.

- Having your own EMF dosimeter or detector to find out any unwanted radiation before being too late.

\subsection{Standards}

Each standard is developed for certain usage. According to our usual case, in our life style we need to know the boundaries of what we call as Public levels of safety. The ICNIRP [1] has defined the limitations for two groups of "Occupational" and "general public" in different reports for certain short exposing duration. Its reports cover the full frequency band from some $\mathrm{kHz}$ up to $300 \mathrm{GHz}$. Though other organizations like FCC, IEEE and NRPB93 have different definitions but we believe that the one which has stronger care to health is preferred. Therefore, the standard which based on clinical experiments has been chosen rather than the one which based on compatibility to existed equipments.

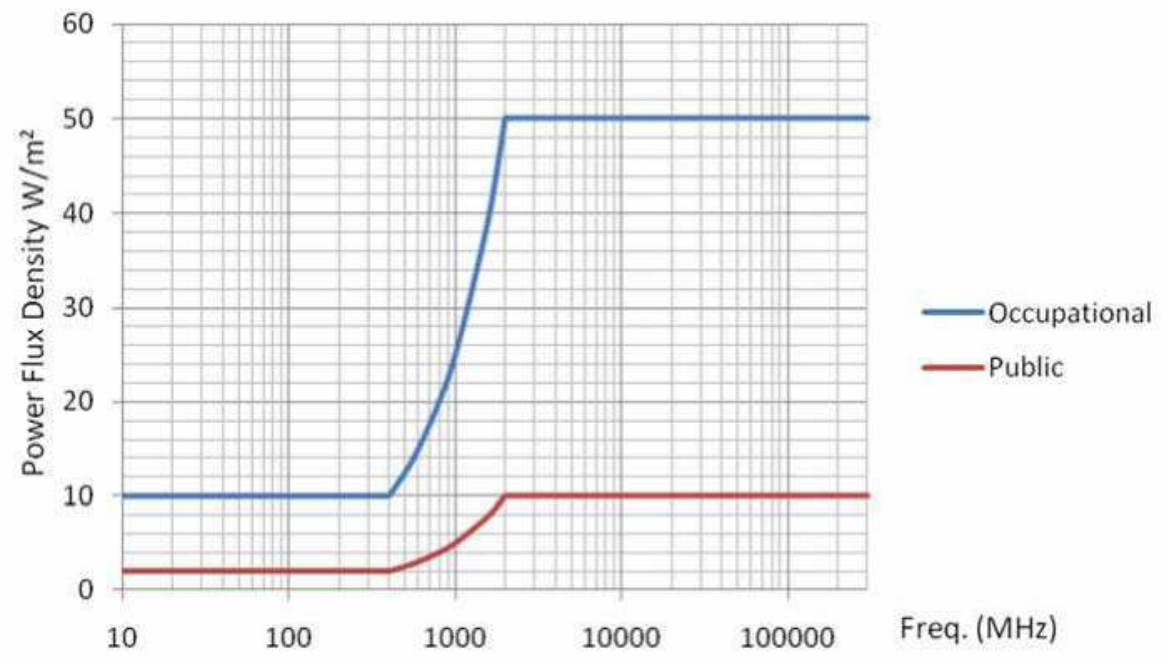

Fig. 15. Power Flux density curves for occupational and public, based on ICNIRP recommendation 


\begin{tabular}{|lrr|}
\hline Frequency $(\mathrm{MHz})$ & $\begin{array}{c}\text { Power flux density } \\
\text { Occupational }\end{array}$ & $\begin{array}{r}\left(\mathrm{Wm}^{-2}\right) \\
\text { Public }\end{array}$ \\
\hline $10-400$ & 10 & 2 \\
$400-2000$ & $\mathrm{f} / 200$ & $\mathrm{f} / 40$ \\
$2000-300000$ & 10 & 50 \\
\hline
\end{tabular}

Table 4. Power Flux density for occupational and public, based on ICNIRP recommendation

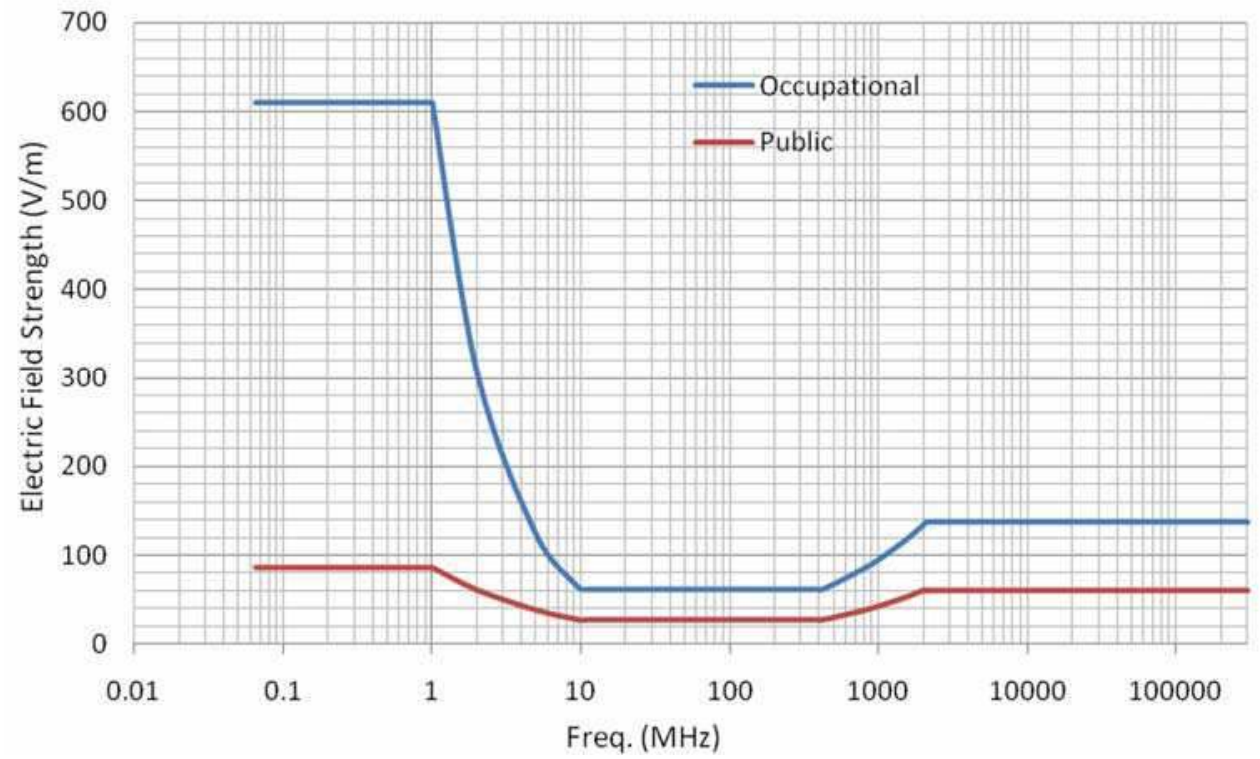

Fig. 16. Electric field strength curves for occupational and public, based on ICNIRP recommendation

\begin{tabular}{|lrr|}
\hline Frequency (MHz) & $\begin{array}{r}\text { Electric Field Strength } \\
\text { Occupational }\end{array}$ & \multicolumn{1}{c|}{$\begin{array}{c}\text { Public } \\
\text { Public }\end{array}$} \\
\hline $0.065-1$ & 610 & 87 \\
$1-10$ & $610 / \mathrm{f}$ & $87 / \mathrm{f}^{0.5}$ \\
$10-400$ & 61 & 28 \\
$400-2000$ & $3 \mathrm{f}^{0.5}$ & $1.375 \mathrm{f}^{0.5}$ \\
$2000-300000$ & 137 & 61 \\
& & \\
\hline
\end{tabular}

Table 5. Electric field strength for occupational and public, based on ICNIRP recommendation 


\begin{tabular}{|lrr|}
\hline & $\begin{array}{c}\text { Magnetic Field Strength } \\
\text { Frequency (MHz) }\end{array}$ & \multicolumn{1}{c|}{$\begin{array}{c}\text { Am-1) } \\
\text { Occupational }\end{array}$} \\
\hline $0.065-1$ & $1.6 / \mathrm{f}$ & $0.73 / \mathrm{f}$ \\
$1-10$ & $1.6 / \mathrm{f}$ & $0.73 / \mathrm{f}$ \\
$10-400$ & 0.16 & 0.073 \\
$400-2000$ & $0.008 f^{0.5}$ & $0.0037 f^{0.5}$ \\
$2000-300000$ & 0.36 & 0.16 \\
\end{tabular}

Table 6. Magnetic field strength for occupational and public, based on ICNIRP recommendation

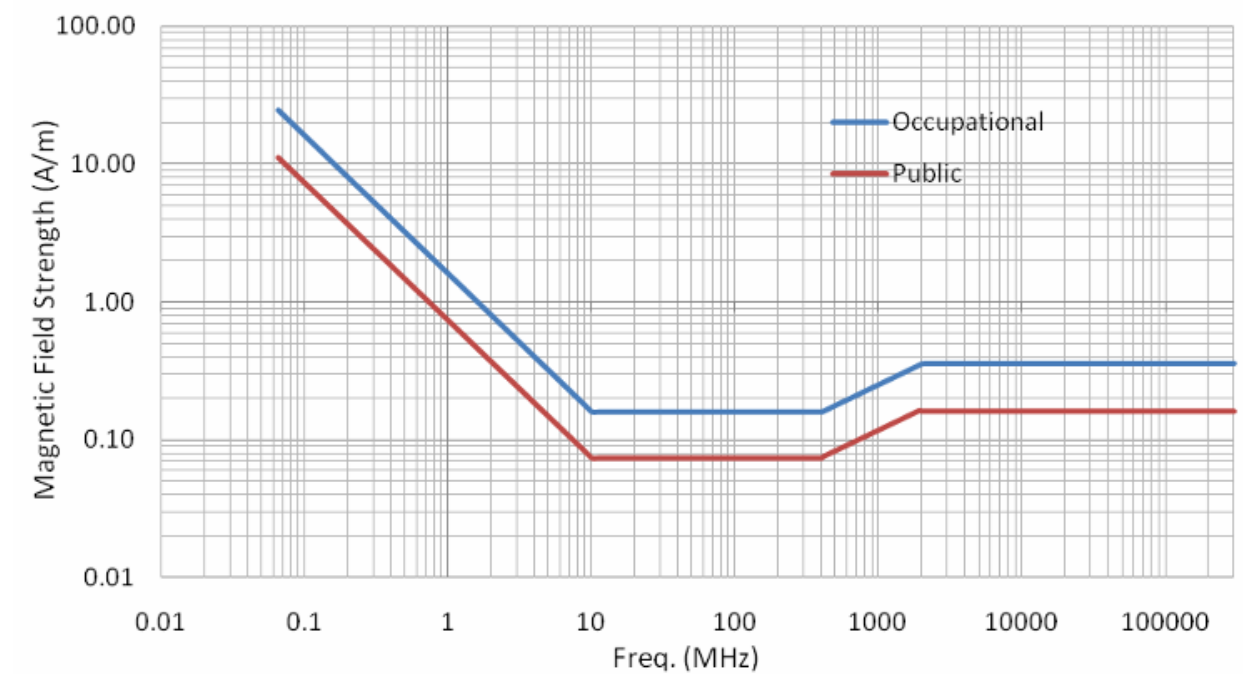

Fig. 17. Magnetic field strength curves for occupational and public, based on ICNIRP recommendation

\section{Conclusion}

A brief introductory to Radio-wave radiation is given and measuring techniques for each region of radiation is also discussed. There are different definitions regarding safety standards. The main problem for using such safety recommendations is misusing the equipments due to un-aware of EMF exposure effects, lack of general knowledge and society culture. As an example even a standard mobile handset that we called safe, can be harmful if user call duration exceeds its recommended talking time (max $3 \mathrm{~min} /$ resting time for rehabilitation). This long calling time on mobile handsets is what we have seen in some countries since people use the mobile phone same as fixed line telephone. Therefore, this misusing can be the main problem to any radiation sources but there are some good 
progresses in terms of EMF exposure prevention methods like radiation absorbers to reduce such EMF exposure on human's body. Using the various absorbers, shielding, and controlling the leakage of cables are some of those methods. Effects of EMF radiation on children and adults are not the same so taking more care for children is the good advisory to keep in mind.

\section{References}

[1] International Commission on Non-Ionizing Radiation Protection, ICNIRP, EMF guidelines, http://www.icnirp.de

[2] Karttunen, H., et al., (2007), Fundamental Astronomy, $5^{\text {th }}$ edition, Springer, New York, ISBN 978-3-540-34143-7

[3] Milligan, T.A., (2005), Modern Antenna Design, 2nd edition, John Wiley \& Sons, Inc., New Jersey, ISBN-13978-0-471-45776-3

[4] Balanis, C.A., (2005), Antenna Theory Analysis and Design, 3 $3^{\text {rd }}$ edition, John Wiely \& Sons, Inc., New Jersey, pp. 34-36, ISBN-0-471-66782-X

[5] Barnes, F.S., Greenebaum, B., (2007), Bioengineering and Biophysical Aspects of Electromagnetic Fields, Handbook of Biological effects of Electromagnetic Fields, $3^{\text {rd }}$ edition, CRC Taylor \& Francis press, ISBN-0-8493-9539-9

[6] Kitchen, R.,(2001). RF \& Microwave Radiation Safety Handbook, pp. 68, ISBN: 0-7506-43552, Newnes, London

[7] Jenn, D. (2009). Electromagnetic Radiation Hazards, EC3630 radiowave propagation, pp.11, Naval Postgraduate school, department of Electrical \& Computer Engineering, Monterey, California

[8] Adir, E.R, (1987). Thermophysical Effects of Electromagnetic Radiation, IEEE Engineering in Medicine and Biology Magazine, pp.37-41

[9] Chen, J. \& Gandhi, O.P.(1989). RF Currents induced in an anatomically based model of a human for plane-wave exposures (20 to 100MHz), Health Physics, Vol. 57, No. 1, pp. 89-98

[10] Durney, C.H. et al.,( 2002), Radiofrequency Radiation Dosimetry Handbook, $4^{\text {th }}$ edition, The University of Utah, Salt Lake city, USA

[11] Gandhi O.P. et al (1980). State of the knowledge for Electromagnetic Absorbed Dose in Man and Animals; Proc. IEEE, Vol.68, No.1, Jan 1980, pp. 24-32

[12] ICNIRP (1998), Guidelines for limiting exposure to time-varying electric, magnetic and electromagnetic fields (up to 300GHz), Health Physics, Vol. 74, No. 4, pp. 494-522.

[13] Kheifets, L. (2001). EMF Epidemiology: State of science, WHO Meeting on EMF Biological Effects E Standards Harmonization in Asia and Oceania 22 - 24 October, 2001, Seoul, Korea

[14] Masao Taki, (2001). CHARACTERISTICS, DOSIMETRY \& MEASUREMENT OF EMF, WHO Meeting on EMF Biological Effects \& Standards Harmonization in Asia and Oceania 22 - 24 October, 2001, Seoul, Korea

[15] NRPB, (1992). Electromagnetic Fields and the Risk of Cancer; report of an ADVISORY GROUP ON Non-Ionizing Radiation; NRPB Document Vol. 3 , No.1, HMSO Books, London ISBN-0-85951-346-7

[16] Pirogova,E., Vojisavljevic,V., Cosic, I., (2010). New developments in Biomedical Engineering, Ch 5., InTech, ISBN 978-953-7610-57-2 
[17] Pirogova, E., Vojisavljevic,V., Cosic, I.,(2009) Biological effects of electromagnetic radiation, Recent Advances in Biomedical Engineering, ISBN 978-953-7619-X-X, (accepted for publication), In-Tech Vienna, Austria.

[18] Schilling, C.J.(2000). Case report: Effects of exposure to very high frequency radio frequency radiation on six antenna engineers in two incidents; Occup. Med.,Vol. 50, No. 1, pp.49-56

[19] Vorst, A.V., Rosen, A., Kotsuka, Y., (2006). RF/Microwave Interaction with biological Tissue. Wiley-interscience, IEEE Press, pp. 93-140 


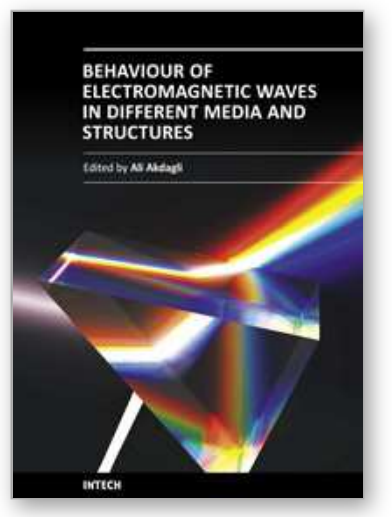

\section{Behaviour of Electromagnetic Waves in Different Media and Structures \\ Edited by Prof. Ali Akdagli}

ISBN 978-953-307-302-6

Hard cover, 440 pages

Publisher InTech

Published online 09, June, 2011

Published in print edition June, 2011

This comprehensive volume thoroughly covers wave propagation behaviors and computational techniques for electromagnetic waves in different complex media. The chapter authors describe powerful and sophisticated analytic and numerical methods to solve their specific electromagnetic problems for complex media and geometries as well. This book will be of interest to electromagnetics and microwave engineers, physicists and scientists.

\section{How to reference}

In order to correctly reference this scholarly work, feel free to copy and paste the following:

Mahmoud Moghavvemi, Farhang Alijani, Hossein Ameri Mahabadi and Maryam Ashayer Soltani (2011). Exposing to EMF, Behaviour of Electromagnetic Waves in Different Media and Structures, Prof. Ali Akdagli (Ed.), ISBN: 978-953-307-302-6, InTech, Available from: http://www.intechopen.com/books/behavior-ofelectromagnetic-waves-in-different-media-and-structures/exposing-to-emf1

\section{INTECH}

open science | open minds

\author{
InTech Europe \\ University Campus STeP Ri \\ Slavka Krautzeka 83/A \\ 51000 Rijeka, Croatia \\ Phone: +385 (51) 770447 \\ Fax: +385 (51) 686166 \\ www.intechopen.com
}

\author{
InTech China \\ Unit 405, Office Block, Hotel Equatorial Shanghai \\ No.65, Yan An Road (West), Shanghai, 200040, China \\ 中国上海市延安西路65号上海国际贵都大饭店办公楼 405 单元 \\ Phone: +86-21-62489820 \\ Fax: $+86-21-62489821$
}


(C) 2011 The Author(s). Licensee IntechOpen. This chapter is distributed under the terms of the Creative Commons Attribution-NonCommercialShareAlike-3.0 License, which permits use, distribution and reproduction for non-commercial purposes, provided the original is properly cited and derivative works building on this content are distributed under the same license. 